\title{
Chlorambucil and lomustine (CL56) in absolute hormone refractory prostate cancer: re-induction of endocrine sensitivity an unexpected finding
}

\author{
J Shamash*,', G Dancey', C Barlow', P Wilson', W Ansell' and RTD Oliver' \\ 'Department of Medical Oncology, St Bartholomew's Hospital, London ECIA 7BE, UK
}

The management of androgen independent prostate cancer is increasingly disputed. Diethylstilbestrol and steroids have useful second-line activity in its management. The value of chemotherapy still remains contentious. This paper reports a phase 2 study of two orally active chemotherapy drugs in patients who are absolutely hormone refractory having failed primary androgen blockade and combined oestrogens and corticosteroids. In total, 37 patients who were biochemically castrate with absolute hormone refractory prostate cancer and performance status of $0-3$ were enrolled. Therapy consisted of chlorambucil I $\mathrm{mg} \mathrm{kg}^{-1}$ given as $6 \mathrm{mg}$ a day until the total dose was reached and lomustine $2 \mathrm{mg} \mathrm{kg}^{-1}$ given every 56 days (CL56). During this time all hormone therapy was stopped. One patient normalised his PSA with a further two having a greater than $50 \%$ decline leading to an objective response rate of $10 \%$. The median time to progression was 3.6 months with an overall survival of 7.1 months. The median survival of this group of patients from first becoming androgen independent was 23.5 months. Eight of 17 (47\%) patients who were subsequently rechallenged with hormonal therapy following failure of chemotherapy had a further PSA reduction, three (17\%) of which were $>50 \%$. The median progression-free interval for the eight patients was 4 months. In conclusion, CL56 has a low objective response rate in the management of absolute hormone refractory prostate cancer. Toxicity was mild. Re-induction of hormone sensitivity following failure of chemotherapy was an unexpected finding that requires further study.

British Journal of Cancer (2005) 92, 36-40. doi: 10.1 038/sj.bjc.6602263 www.bjcancer.com

Published online 30 November 2004

(c) 2005 Cancer Research UK

Keywords: prostate cancer; hormone resistant; chemotherapy

The majority of patients with locally advanced or metastatic prostate cancer treated by continuous androgen deprivation using either maximum androgen blockade (MAB) or $\mathrm{GnRH}$ analogue with deferred antiandrogens and then antiandrogen withdrawal ultimately become hormone resistant after 1-2 years treatment. Once hormone resistant their median survival then falls to about 1 year (Tannock et al, 1996).

Following the publication of three phase III studies comparing mitoxantrone and prednisone to prednisone alone in androgen independent prostate cancer, which demonstrated an improvement in symptom control despite failure to improve survival, chemotherapy has become accepted as having a role at this point in the disease (Tannock et al, 1996). More recently, the presentation of two large randomised phase III trials comparing mitoxantrone and docetaxel showed a significant survival advantage in favour of docetaxel (Eisenberger et al, 2004; Petrylak et al, 2004).

\footnotetext{
*Correspondence: Dr J Shamash, St Bartholomew's Hospital, Department of Medical Oncology, West Smithfield, London ECIA 7BE, UK; E-mail: jonathan.shamash@bartsandthelondon.nhs.uk Received 31 August 2004; revised 20 October 2004; accepted 20 October 2004; published online 30 November 2004
}

Oestrogens such as fosfosterol (Orlando et al, 2000) and diethylstilbestrol may produce responses in androgen independent patients. In one study the combination of low-dose diethystilboestrol and hydrocortisone produced a PSA response in $76 \%$ (Farrugia et al, 2000). Preliminary data suggesting that the response was more durable with dexamethasone than cortisone (Bhattacharyya et al, 2003) has led to that combination becoming the standard of care in our unit with chemotherapy only being used after second-line endocrine treatment fails.

In an attempt to investigate the true response rate in patients who had failed primary androgen deprivation as well as both oestrogens and corticosteroids (during which GnRH analogue therapy was stopped). A phase II chemotherapy study was undertaken. Patients who were not biochemically castrate on steroids and oestrogens and had a rising PSA had GnRH therapy reinstituted and only when this failed to control their PSA were they eligible for chemotherapy. To increase patient acceptance two orally active chemotherapy agents, chlorambucil and lomustine, were selected. These were active drugs when tested in the early 1980s by less stringent criteria than used today and had response rates of 30-46\% (Catane et al, 1978; Loening et al, 1981; Herr, 1982; Ruff et al, 1989). Although these earlier results are of use in suggesting some activity, the absolute percentages cannot be compared to the more recent data from the post-PSA era. As the combination had shown good activity with low toxicity in 
refractory lymphoma (Oza et al, 1993), we set out to study this combination in absolute hormone refractory prostate cancer. This paper reports these preliminary findings.

\section{PATIENTS AND METHODS}

Patients were eligible for the study if they had histologically documented adenocarcinoma of the prostate with progression despite androgen deprivation followed by second-line hormonal therapy with steroids and oestrogens and were chemotherapy naïve.

On becoming androgen independent (as judged by rising PSA in the presence of castrate levels of testosterone $\left.\left(<1.5 \mathrm{nmoll}^{-1}\right)\right)$ patients were treated with diethylstilbestrol $1 \mathrm{mg} \mathrm{day}^{-1}$ combined with a steroid (either dexamethasone $2 \mathrm{mg}^{-1 a y^{-1}}$ or hydrocortisone $20 \mathrm{mg}$ twice a day or prednisolone $20 \mathrm{mg}$ day $^{-1}$ ) without a $\mathrm{GnRH}$ analogue. Following documented biochemical or symptomatic progression, the serum testosterone was rechecked and if they were still biochemically castrate they were eligible for chemotherapy. If not, androgen deprivation was recommenced and only if there were no response to this would chemotherapy be offered. Patients had their GnRH therapy stopped at the start of chemotherapy.

Assessable disease consisted of soft tissue disease or a rising PSA. Patients were required to have an Eastern Cooperative Oncology Group status of 0-3. Required haematological parameters were platelets greater than $100 \times 10^{9} \mathrm{l}^{-1}$, granulocytes greater than $3 \times 10^{9} \mathrm{l}^{-1}$ and haemoglobin greater than $90 \mathrm{gl}^{-1}$ (transfusions were permitted). The study was approved by Local Research Ethics Committee (LREC) and all patients gave written informed consent prior to participation.

\section{Treatment and evaluation}

Treatment consisted of chlorambucil at $1 \mathrm{mg} \mathrm{kg}^{-1}$ (given at $6 \mathrm{mg}$ a day until the total dose reached) and lomustine at $2 \mathrm{mg} \mathrm{kg}^{-1}$ on day 1 . The dose of lomustine was reduced to $1 \mathrm{mg} \mathrm{kg}^{-1}$ if radiotherapy to more than three sites had previously been given. Granisetron $1 \mathrm{mg}$ orally day 1 , dexamethasone $8 \mathrm{mg}$ day 1 and $4 \mathrm{mg} \mathrm{day}^{-1}$ on days 2 and 3 as well as metoclopramide $20 \mathrm{mg} 3 \times 1$ day for 3 days were prescribed as antiemetics. This cycle was repeated every 56 days (CL56). Patients were asked to complete quality of life forms both general and prostate specific. (EORTC QLQ 30 with PR 25 prior to treatment and on day 1 on subsequent cycles). Once started on chemotherapy all hormone therapy was stopped, including if possible, a phased reduction of steroids. If pain worsened or the patient developed steroid deficiency symptoms, they remained on their original dose of steroids until it was clear whether they were responding when a further phased reduction was attempted.

Patients were evaluated for response at the end of cycle 1 . If the disease was responding or stable, further cycles were given to a maximum of six cycles. Progression (PD) on PSA was defined as an increase of greater than $25 \%$ over nadir that was then confirmed with a second rising PSA. Those patients with soft tissue disease were assessed on CT scan. Repeat blood tests were carried out on days 1, 22 and 36 of each cycle, including a full blood count, urea and electrolytes, alkaline phosphatase and PSA.

The date of progression was defined as that of the first CT that showed new lesions or a $25 \%$ increase in previously measured disease, or showing a rise in PSA. PSA responses were evaluated using the guidelines from the prostate-specific antigen working group for PSA response in androgen independent disease (Bubley et al, 1999). In the first cycle if the PSA was rising but there were clinical signs of improvement then a second cycle was given. If it became clear that the PSA continued to rise in the second cycle then the date of progression was taken on the first confirmed rise in PSA. In some patients, this was 21 days into the first cycle. For those whose PSA rose in the first 8 weeks and then fell, the date of progression was the first confirmed rise in the second or subsequent cycle. A $50 \%$ fall in PSA maintained for 4 weeks was termed a partial response (PR). Patients whose PSA stabilised for more than 8 weeks, that is, did not rise by $25 \%$ or fall by greater than $50 \%$ were considered as stable disease. Normalisation of PSA (less than $4 \mathrm{ng} \mathrm{ml}^{-1}$ ) confirmed for 1 month was termed a complete response (CR).

\section{Dose modifications}

Prior to each chemotherapy cycle, platelets greater than $80 \times 10^{9} 1^{-1}$ and white cell count greater than $3.0 \times 10^{9} 1^{-1}$ were needed. Patients with low counts were delayed for a week or until the blood count recovered. Failure to recover counts in 4 weeks meant the patient went off study.

If a delay was required, the doses of lomustine and chlorambucil were reduced by $25 \%$. If the nadir platelet count was $<20 \times 10^{9} 1^{-1}$, the dose of lomustine was reduced by $50 \%$ on subsequent cycles. If nadir platelet count was between 21 and $49 \times 10^{9} 1^{-1}$, the subsequent lomustine dose was reduced by $25 \%$.

Patients who had received prior treatment with strontium or previous radiotherapy to three or more sites received a reduced dose of lomustine of $1 \mathrm{mg} \mathrm{kg}^{-1}$. If the nadir platelet count was greater than $50 \times 10^{9}$, the lomustine dose was increased to $2 \mathrm{mg} \mathrm{kg}^{-1}$ on subsequent cycles.

\section{Statistical design and analyses}

The log-rank test was used to look at which variables were significant on univariate analysis for overall survival and progression-free survival. The Wilcoxon matched pairs signed rank sum test was used to look at changes in Quality of Life scores from baseline to 8 weeks. Fishers exact test was used when the numbers expected were less than 5 .

\section{RESULTS}

\section{Patient characteristics (Table 1)}

Between the 3 November 2000 and the 20 September 2002, 37 patients were recruited into this study, their median performance status was 1 (range $0-3$ ). A total of $89 \%$ were symptomatic and $19 \%$ had extensive visceral disease (liver or lung metastases). Only $48 \%$ had normalised their PSA with androgen deprivation despite the fact that $49 \%$ had received initial MAB. The median time to androgen independence for the group was 23.5 months and the median time between androgen independence and receiving chemotherapy was 14 months.

\section{Toxicity (see Table 2)}

A median of two cycles of therapy was administered. No grade 4 toxicity was seen. The most significant problems were malaise (grade 3 in 14\%), and constipation (grade 3 in 12\%), which reflects in part the high frequency of opioid analgesia in this group of advanced end stage patients. Haematological toxicity was mild with only $4 \%$ having grade 3 leukopenia and $11 \%$ grade 3 thrombocytopenia.

\section{Treatment outcomes}

The overall results are summarised in Table 3. Biochemical response rate to CL56 was $10 \%$ (one normalisation of PSA and two with a greater than $50 \%$ response). An additional $46 \%$ achieved stabilisation of their disease beyond 8 weeks and overall $54 \%$ had a symptomatic response. The median time to progression was 3.6 
Table I Pretreatment patient characteristics

\begin{tabular}{|c|c|}
\hline & Patient characteristics \\
\hline Number of patients & 37 \\
\hline Median age (range) & 71.4 years $(57.6-83.9)$ \\
\hline \multicolumn{2}{|l|}{ Disease extent } \\
\hline Localised & I \\
\hline Bone mets only & 13 \\
\hline Bone+nodal disease & 16 \\
\hline Bone+liver/lung & 7 \\
\hline \multicolumn{2}{|l|}{ Performance score } \\
\hline 0 & 2 \\
\hline I & 18 \\
\hline 2 & II \\
\hline 3 & 5 \\
\hline Missing & । \\
\hline \multicolumn{2}{|l|}{ Symptomatic } \\
\hline No & 3 \\
\hline Yes & 33 \\
\hline Missing & । \\
\hline \multicolumn{2}{|l|}{ Primary therapy } \\
\hline $\mathrm{GnRH}$ & 18 \\
\hline MAB & 13 \\
\hline Orchidectomy & 3 \\
\hline Antiandrogen monotherapy & 3 \\
\hline \multicolumn{2}{|l|}{ PSA levels at start CL56 } \\
\hline Median and (range) & $183.5(\mid 1.3-1560)$ \\
\hline \multicolumn{2}{|l|}{ Alkaline phosphatase at start of CL56 } \\
\hline$\leqslant 120$ & 18 \\
\hline$>120$ & 19 \\
\hline \multicolumn{2}{|l|}{ Gleason score } \\
\hline $8-10$ & 6 \\
\hline $5-7$ & 17 \\
\hline$\leqslant 4$ & 3 \\
\hline Missing & 11 \\
\hline \multicolumn{2}{|l|}{ PSA normalised with prior androgen deprivation } \\
\hline No & 16 \\
\hline Yes & 15 \\
\hline Missing & 6 \\
\hline Median time to androgen independence (Al) & 25 months (range $4.4-136.7$ ) \\
\hline Number $\mathrm{Al}<2$ years & 17 \\
\hline Number $\mathrm{Al}>2$ years & 20 \\
\hline Median time Al to start study & 14.3 months (range 1.8-46.2) \\
\hline Number Al to start study < I year & 17 \\
\hline Number Al to start study $>$ I year & 20 \\
\hline
\end{tabular}

months (95\% CI 2.3-4.9) (CR/PR 4.4 months, SD 3.7 months, PD 0.9 months) with an overall survival of 7.1 months (CR/PR 8.8 months, SD 10.9 months, PD 4.8 months). The median survival from becoming androgen independent was 23.5 months (95\% CI 17.0-29.8).

Eight out of 17 patients with SD had an initial rise in PSA in the first 3-8 weeks (median rise 99\% range 8-794\%) followed by plateau and then a fall 2 weeks later (median fall $29 \%$ from the peak, range 7-63\%). In three of eight, these declines lasted more than 24 weeks though in two of the three, the minimum was still higher than the pretreatment level.

Those who had SD at 8 weeks had a different subsequent pattern of symptom response and PSA change than those who progressed.
Table 2 WHO toxicity grade per cycle (in percentages)

\begin{tabular}{lccc}
\hline & Grade $\mathbf{~ I ~ - ~} \mathbf{( \% )}$ & Grade $\mathbf{3}(\%)$ & Grade $\mathbf{4}$ (\%) \\
\hline Infection & 4 & 0 & 0 \\
Malaise & 29 & 14 & 0 \\
Taste & 4 & 0 & 0 \\
Nausea & 14 & 2 & 0 \\
Vomiting & 2 & 0 & 0 \\
Constipation & 14 & 12 & 0 \\
Diarrhoea & 0 & 0 & 0 \\
Stomatitis & 0 & 0 & 0 \\
Anorexia & 17 & 8 & 0 \\
Alopecia & 0 & 0 & 0 \\
Dyspnoea & 10 & 0 & 0 \\
Neuropathy & 0 & 0 & 0 \\
Hb & & & 0 \\
Wbc & 15 & 4 & 0 \\
Platelets & 20 & 4 & 0 \\
\hline
\end{tabular}

Table 3 Response and survival following CL56 and subsequent response to further hormone therapy

\begin{tabular}{ll}
\hline Median no. of cycles: & 2 (range I-6) \\
Response to CL56 & 1 \\
CR & 2 \\
PR & 17 \\
SD & 12 \\
PD & 5 \\
NE & \\
Response rate & $3 / 32$ (10\%) \\
& \\
Stabilisation rate (SD or better) & $20 / 32$ (63\%) \\
& \\
Symptomatic improvement (24 evaluable) & 13 \\
No & 11 \\
Yes & \\
Alk Phos response by week 8 (14 evaluable) & 11 \\
No & 3 \\
Yes & 7.1 months (95\% Cl 6.2-8.0) \\
Median survival & 3.6 months (95\% Cl 2.3-4.9) \\
Median time to progression & $5 / 37$ \\
PF at 6 months & 23.5 months (95\% Cl 17.2-29.8) \\
Median survival following Al & \\
Post-CL56 hormones & 17 \\
Yes & \\
Response to post-CL56 hormone therapy & 9 \\
Yes & \\
$>50 \%$ & 3 \\
\hline
\end{tabular}

The PSA levels (median $198 \mathrm{ng} \mathrm{ml}^{-1}$ for SD and $206 \mathrm{ng} \mathrm{ml}^{-1}$ for PD) and PSA doubling time prior to the start of chemotherapy (median 80 days for SD and 78 days for PD/NE) were very similar for the SD group and the PD/NE group. Those who had objective biochemical responses had lower PSA levels (median $80 \mathrm{ng} \mathrm{ml}^{-1}$ ) and doubling time (median 46 days) at the start of chemotherapy but numbers were small. However after treatment, there was a marked difference in post-treatment PSA doubling time between the SD and PD groups (217 vs 29 days).

Following progression on CL56, endocrine treatment was restarted in 17 patients (Table 4). Two orchidectomised patients failed to respond to addition of antiandrogens, though the only 
Table 4 Post-CL56 hormone characteristics and subsequent response in 17 patients

Post-CL56 treatment

\begin{tabular}{|c|c|c|c|c|c|c|c|c|c|}
\hline $\begin{array}{l}\text { Patient } \\
\text { no. }\end{array}$ & Castrate & $\begin{array}{c}\text { GnRH } \\
\text { analogue }\end{array}$ & MAB & $\begin{array}{c}\% \text { PSA } \\
\text { decline }^{a}\end{array}$ & $\begin{array}{l}\text { Duration } \\
\text { (months) }\end{array}$ & Stilb/steroid & $\begin{array}{c}\% \text { PSA } \\
\text { decline }^{a}\end{array}$ & $\begin{array}{l}\text { Duration } \\
\text { (months) }\end{array}$ & $\begin{array}{l}\text { Time from CL56 to } \\
\text { postchemotherapy hormone } \\
\text { treatment (months) }\end{array}$ \\
\hline 1 & Yes & Yes & Yes & PD & & No & - & - & 3.6 \\
\hline $2^{b}$ & Yes & No & Yes & PD & & Yes & $90 \%$ & || & 19.0 \\
\hline 3 & Yes & Yes & Yes & PD & & No & - & - & 3.2 \\
\hline 4 & Yes & Yes & No & $10 \%$ & 2.5 & Yes & $20 \%$ & 4 & 8.0 \\
\hline 5 & Yes & Yes & No & PD & - & Yes & PD & - & 5.5 \\
\hline 6 & Unknown & No & No & - & - & Yes & $45 \%$ & 4 & 4.6 \\
\hline 7 & Unknown & Yes & Yes & PD & - & Yes & PD & - & 4.0 \\
\hline $8^{b}$ & Yes & No & Yes & PD & - & - & - & - & 8.2 \\
\hline 9 & No & Yes & No & $55 \%$ & 6 & Yes & PD & - & 9.1 \\
\hline 10 & Unknown & Yes & Yes & $97 \%$ & $6.0+$ & No & - & - & |6.| \\
\hline |1 & Unknown & Yes & No & $45 \%$ & 2 & No & - & - & 3.8 \\
\hline 12 & Yes & Yes & No & $7 \%$ & 3 & No & - & - & 7.2 \\
\hline 13 & Yes & Yes & No & PD & - & - & - & - & 2.5 \\
\hline 14 & Yes & Yes & No & PD & - & - & - & - & 3.8 \\
\hline 15 & Unknown & Yes & Yes & $30 \%$ & 3 & Yes & PD & - & \\
\hline 16 & Yes & No & Yes & PD & - & - & - & - & 3.7 \\
\hline 17 & No & Yes & No & PD & - & Yes & $15 \%$ & 2 & 3.8 \\
\hline
\end{tabular}

$\mathrm{MAB}=$ maximum androgen blockade. Stilb/steroid = diethylstilbestrol and steroid. ${ }^{\mathrm{a} F r o m}$ the start of hormone therapy. ${ }^{\mathrm{b}}$ Patient had orchidectomy

one of these to be retreated with stilbestrol and dexamethasone after failed antiandrogens responded a second time. In total, 13 patients received GnRH analogue for a second time. There were six PSA falls, two of which were greater than $50 \%$. Six of the 13 patients subsequently received diethylstilbestrol and dexamethasone after further progression on GnRH and two responded. There was in addition one who received diethylstilbestrol and dexamethasone immediately after progression on CL56, and responded with a fall in PSA of $45 \%$. The median time from CL56 to starting hormone therapy was greater in those who subsequently responded to hormones again although this did not reach statistical significance ( 8.0 vs 3.8 months, $P=0.085)$.

Hormone profiles (LH, FSH and testosterone) were repeated in nine patients before secondary endocrine treatment was restarted. Two were found not to be castrate and both responded to subsequent treatment ( 15 and $55 \%$ falls in PSA falls, respectively). Seven were castrate and two responded.

A total of 17 patients, who completed at least two courses of treatment, returned quality of life questionnaires. Eight patients showed some improvement (median improvement +1.5 (quality of life raw score)). In four patients there was no change. In five, quality of life declined (median decline 2.0). There was no clear relationship between Quality of Life changes and tumour response.

\section{Prognostic factors}

In terms of overall survival and time to progression, the following were analysed: Gleason score, normalisation of PSA with prior androgen deprivation, raised alkaline phosphatase, performance status, PSA level, time to androgen independence, age, previous steroid use (dexamethasone vs alternative steroid), period of time of androgen independence prior to chemotherapy.

Of these, on univariate analyses only raised alkaline phosphatase (5.5 months $v s 8.8, P=0.048)$, PSA above median $\left(>185 \mathrm{ng} \mathrm{ml}^{-1}\right)$ (5.5 vs 8.8 months $P=0.024$ ) and time to androgen independence of $<1$ year prior to chemotherapy ( $5.5 v s>6.4$ months $P=0.03$ ) were significant for overall survival. For progression-free survival, only prior dexamethasone $v s$ another steroid (4.3 vs 2 months $P=0.013)$ and time to androgen independence of $>2$ years $(4.2 \mathrm{vs}$ 2.4 months $P=0.049$ ) were significant.

\section{DISCUSSION}

The objective response rate to the combination of chlorambucil and lomustine (CL56) was modest (10\%) and at first sight not very encouraging.

The study was undertaken with these two drugs because the response rate when the two drugs were used together in chemorefractory lymphoma was higher than when used as single agents (Oza et al, 1993).

There was a suggestion that patients with a lower PSA might be more likely to respond as all responses occurred in patients with PSA $<110 \mathrm{ng} \mathrm{ml}^{-1}$ (three out of 14 responses, PSA $\geqslant 110 \mathrm{ng} \mathrm{ml}^{-1}$ zero out of 18 responses ( $P=0.04$ two-tailed Fisher's exact test).

Patients who had stable disease at 8 weeks had a change in their PSA velocity with a substantial reduction in doubling time during chemotherapy. With the use of PSA velocity as a surrogate marker being increasingly accepted, such findings may assume greater significance (Carter et al, 2003; D'Amico et al, 2003; Rini et al, 2003). The lower response rate in this study particularly in comparison to newer data from taxanes based studies (Eisenberger et al, 2004; Petrylak et al, 2004) may in part be explained by the fact that the patients in this study were resistant to corticosteroids and oestrogens as well as to androgen deprivation.

The action of steroids in androgen independent prostate cancer prior to chemotherapy appears more complicated than first thought. The rationale for their use and dosing in this setting was to suppress adrenal production of androgens. It appears that other mechanisms may be important as different steroids have different PSA response rates. In the recent preliminary analysis of a randomised trial comparing dexamethasone alone to dexamethasone and diethylstilbestrol (Shamash et al, 2004), 51\% had a PSA response to dexamethasone. This is higher than the PSA response to hydrocortisone - 21\% (Dawson et al, 1995; Kantoff et al, 1999), or prednisone - 17\% (Dowling et al, 2001; Berry et al, 2002). One explanation for this may be that receptors other than the androgen receptor may be more important than previously appreciated in determining prostate cancer responses. This raises the question as to whether the hormonal responses postchemotherapy represent separate clones being suppressed or whether the chemotherapy is modulating the plasticity of the receptor profile on the tumour cell. 
It is also possible that the routine use of MAB in some studies would have removed any androgen sensitive clones that had survived GnRH monotherapy and it is these clones that were responsible for the re-response to $\mathrm{GnRH}$ therapy following the cessation of chemotherapy in this study.

A criticism of this study is that patients were not androgen suppressed during chemotherapy. It could be that although most remained biochemically castrate that androgen level could have been kept lower by maintaining androgen deprivation and even a small rise within the castrate range was responsible for the growth of androgen dependent clone, which then responded to the reinduction of androgen deprivation following the failure of chemotherapy. We do not believe this to be the dominant explanation. There are anecdotal reports of similar secondary responses being seen in breast cancer patients progressing on chemotherapy (Ragaz, 2001), and they provide additional arguments for the use of sequential hormonal and then chemotherapy rather than the use of both modalities consecutively.

\section{REFERENCES}

Berry W, Dakhil S, Modiano M, Gregurich M, Asmar L (2002) Phase III study of mitoxantrone plus low dose prednisone versus low dose prednisone alone in patients with asymptomatic hormone refractory prostate cancer [comment]. J Urol 168: 2439-2443

Bhattacharyya M, Dancey G, Shamash J, Ong J, Ansell W, Wilson P, Oliver RTD (2003) Dexamethasone as an alternative to cortisone in combination with stilboestrol for hormone refractory prostate cancer. Br J Cancer 88(Suppl 1): S62 (abstr 147)

Bubley GJ, Carducci M, Dahut W (1999) Eligibility and response guidelines for phase II clinical trials in androgen-independent prostate cancer: recommendations from the prostate-specific antigen working group. J Clin Oncol 17: $3461-3467$

Carter CA, Donahue T, Sun L, Wu H, McLeod DG, Amling C, Lance R, Foley J, Sexton W, Kusuda L, Chung A, Soderdahl D, Jackmaan S, Moul JW (2003) Temporarily deferred therapy (watchful waiting) for men younger than 70 years and with low-risk localized prostate cancer in the prostate-specific antigen era. J Clin Oncol 21: 4001-4008

Catane R, Kaufman JH, Madajewicz S (1978) Prednimustine therapy for advanced prostatic cancer. BJU Int 50: 29-32

D’Amico AV, Moul JW, Carroll PR, Sun L, Lubeck D, Chen MH (2003) Surrogate end point for prostate cancer-specific mortality after radical prostatectomy or radiation therapy [comment]. J Natl Cancer Inst 95: 1376-1383

Dawson NA, Cooper MR, Figg WD, Headlee DJ, Thibault A, Bergan RC, Steinberg SM, Sausville EA, Myers CE, Sartor O (1995) Antitumor activity of suramin in hormone-refractory prostate cancer controlling for hydrocortisone treatment and flutamide withdrawal as potentially confounding variables. Cancer 76: $453-462$

Dowling AJ, Panzarella T, Ernst DS, Neville AJ, Moore MJ, Tannock IF (2001) A retrospective analysis of the relationship between changes in serum PSA, palliative response and survival following systemic treatment in a Canadian randomized trial for symptomatic hormone-refractory prostate cancer. Ann Oncol 12: 773-778

Eisenberger MA, de Wit R, Berry W, Bodrogi I, Pluzanska A, Chi I, Oudard S, Christine T, James N, Tannock IF (2004) A multicenter phase III comparison of docetaxel (D)+prednisone (P) and mitoxantrone (MTZ) $+\mathrm{P}$ in patients with hormone-refractory prostate cancer (HRPC). $J$ Clin Oncol 23(2 suppl): (abstr 4)

Farrugia D, Ansell W, Singh M, Philp T, Chinegwundoh F, Oliver RT (2000) Stilboestrol plus adrenal suppression as salvage treatment for patients failing treatment with luteinizing hormone-releasing hormone analogues and orchidectomy. BJU Int 85: 1069-1073

Herr HW (1982) Cyclophosphamide, methotrexate and 5-fluorouracil combination chemotherapy $v s$ chlorethyl-nitrosurea in the treatment of metastatic prostate cancer. J Urol 127: $462-465$
In conclusion, this study has demonstrated that use of a simple oral chemotherapy regimen repeated every 8 weeks sequentially following the failure of oestrogens and steroids in the management of androgen independent prostate cancer produces evidence of antitumour activity in nearly $2 / 3$ rds of such end stage patients based on slowing of tumour doubling time despite a low PSA response rate. It is well tolerated and the survival in this cohort compares favourably with that seen in the current more toxic taxane/estramustine based combinations. There is an urgent need to prospectively analyse secondary hormone responses following chemotherapy so that their frequency and duration may be more accurately determined.

\section{ACKNOWLEDGEMENTS}

We wish to thank the referring urologists from Havering Hospitals Trust, Whipps Cross University Hospital and Barts and the London NHS trust for referring the patients to us for treatment.

Kantoff PW, Halabi S, Conaway M, Picus J, Kirshner J, Hars V, Trump D, Winer EP, Vogelzang NJ (1999) Hydrocortisone with or without mitoxantrone in men with hormone-refractory prostate cancer: results of the cancer and leukemia group B 9182 study [see comment]. J Clin Oncol 17: 2506-2513

Loening SA, Scott WW, deKernion J, Gibbons RP, Johnson DE, Pontes JE, Prout GR, Schmidt JD, Soloway MS, Chu TM, Gaeta JF, Slack NH, Murphy GP (1981) A comparison of hydroxyurea, methyl-chloroethyl-cyclohexy-nitrosourea and cyclophosphamide in patients with advanced carcinoma of the prostate. J Urol 125: $812-816$

Orlando M, Chacon M, Salum G, Chacon DR (2000) Low-dose continuous oral fosfestrol is highly active in 'hormone-refractory' prostate cancer. Ann Oncol 2: 177 - 181

Oza AM, Ganesan TS, Leahy M, Gregory W, Lim J, Dadiotis L, Barbounis V, Jones AE, Amess J, Stansfeld AG, Rohatiner AZS, Wrigley PFM, Lister TA et al (1993) Patterns of survival in patients with Hodgkin's disease: long follow up in a single centre [erratum appears in Ann Oncol 1993 Sep; 4 (8):703]. Ann Oncol 4: 385-392

Petrylak DP, Tangen C, Hussain M, Lara PN, Jones J, Talpin ME, Burch PA, Greene G, Small EJ, Crawford ED (2004) SWOG 99-16: randomized phase III trial of docetaxel(D)/estramurine(E) vs mitoxantrone(M)/predniso$\mathrm{ne}(\mathrm{p})$ in men with androgen-independent prostate cancer (AIPCA). J Clin Oncol 23(2 suppl.): (abstr 3)

Ragaz J (2001) Adjuvant trials of aromatase inhibitors: determining the future landscape of adjuvant endocrine therapy. J Steroid Biochem Mol Biol 79: $133-141$

Rini BI, Weinberg V, Bok R, Small EJ (2003) Prostate-specific antigen kinetics as a measure of the biologic effect of granulocyte-macrophage colony-stimulating factor in patients with serologic progression of prostate cancer. J Clin Oncol 21: 99-105

Ruff P, Derman DP, Weaving A (1989) Sequential hormonal therapy and sequential hormonal and chemotherapy for advanced prostatic cancer. Oncology 45: $288-292$

Shamash J, Barlow C, Heath E, PWilson Ansell W, Somasundram U, Oliver RTD (2004) Interaction between glucocorticoids and estrogen in androgen independent prostate cancer - a randomised phase 2 study. J Clin Oncol 23(Supplement): 443 (abstract 4755)

Tannock IF, Osoba D, Stockler MR, Ernst DS, Neville AJ, Moore MJ, Armitage GR, Wilson JJ, Venner PM, Coppin CM, Murphy KC (1996) Chemotherapy with mitoxantrone plus prednisone or prednisone alone for symptomatic hormone-resistant prostate cancer: a Canadian randomized trial with palliative end points [see comment]. J Clin Oncol 14: $1756-1764$ 